\title{
DRAGLINE-FOLLOWING BY MALE LYCOSID SPIDERS ${ }^{1}$
}

\author{
By William J. TietJen
}

Department of Zoology, Ohio University, Athens, Ohio 45701

Wolf spiders stalk or ambush their prey rather than build preycapture webs. Production of silk by lycosids is important during aerial dispersal via ballooning (Richter, 1970b) and, in some, during post-immobilization wrapping of prey (Rovner and Knost, 1974), and construction of egg sacs or sperm webs (Richter, 1970a). During locomotion both sexes lay down silk draglines that are generally assumed to have a stabilizing or security function (Richter and Van der Krann, 1970). In addition, female draglines induce courtship behavior in male conspecifics and, in some species, males are reported to have followed a female trail, but no systematic analyses of the dragline-following behavior have been attempted (Bristowe and Locket, 1926; Engelhardt, 1964; Kaston, 1936).

The present study is concerned with the trail-following behavior of male Lycosa rabida and L. punctulata. Specific areas of investigation include determination of the use of various appendages during following, analysis of cues involved in initiating and maintaining trail-following, and an interspecific comparison of trailfollowing behavior.

\section{METHODS}

Penultimate and young adult instars of $L$. rabida and L. punctulata were collected near Amesville, Athens County, Ohio, USA, during 1974 and 1976. L. rabida were collected late June through July while $L$. punctulata were collected mid- to late September.

Animals were housed separately in $13 \times 7 \times 6.5 \mathrm{~cm}$ plastic cages painted on two sides to afford visual isolation between animals in adjacent cages. A paper substratum in each cage collected silk used in some experiments and facilitated periodic cleaning of the cages. Water was provided ad libitum via a cotton-stoppered vial, and two Tenebrio sp. larvae were provided per week as food. Cages

\footnotetext{
${ }^{1}$ This study was supported by National Science Foundation Grant BNS 76-15009 to J. S. Rovner.

Manuscript received by the editor September 9, 1977.
} 
containing males were located on shelves along one wall of the laboratory that received indirect sunlight. Laboratory humidity was not controlled (range 36-56\% $\mathrm{RH}$ ) and temperature ranged from $23-28^{\circ} \mathrm{C}$. Cages containing females were placed in a controlled environmental chamber (Frease model 818 ) at $15^{\circ} \mathrm{C}$ night and $20^{\circ} \mathrm{C}$ day and $53-56 \% \mathrm{RH}$, with a photoperiod approximating natural conditions. The lower temperatures were necessary to retard female development and to delay onset of eggsac production, which even occurs eventually in unmated females, making them useless for further experimentation. Females were removed from the environmental chamber and allowed sufficient time to warm to room temperature before experimental use.

In order to lay draglines along predetermined trails spiders were anesthetized with $\mathrm{CO}_{2}$. A thread leash, secured to a hemostat, was tied around the cephalothorax of each spider between the second and third pairs of legs. Upon recovery, the spider was led along a path such that the dragline was laid either directly on the substratum to form "ground lines" or suspended above the substratum by being laid across horizontally placed glass rods to form "aerial lines" (Fig. 1). Lines connecting parts of an artificial plant made of wood dowels were also called "aerial lines." Male draglines or imitation draglines (nylon thread or human hair) were laid in either a continuous or discontinuous manner with the female trail during some experiments.

The test trail was then surrounded by glass walls to provide an arena $(54 \times 64 \mathrm{~cm})$, the position of which was rotated in a random manner between experimental runs. The position, length, and direction of the dragline, including attachment disks (produced by the spider to fix the dragline to a substratum) were recorded on a diagram of the completed path.

Test males were of two physiological conditions: (1) unprimed males, which had not encountered female silk for the previous 72 $\mathrm{hr}$ and (2) primed males, which were induced to court in response to substratum silk from a female cage, and then tested $1 \mathrm{hr}$ later for dragline-following behavior. Experimental trials began when a male released into the arena contacted and explored a female line with his palps. Trials lasted for $5 \mathrm{~min}$, during which time data were recorded in shorthand notation from a distance of $0.5-1.0 \mathrm{~m}$ from the experimental males. To test the response of males to various types of silk, males were released into cages containing either lepi- 


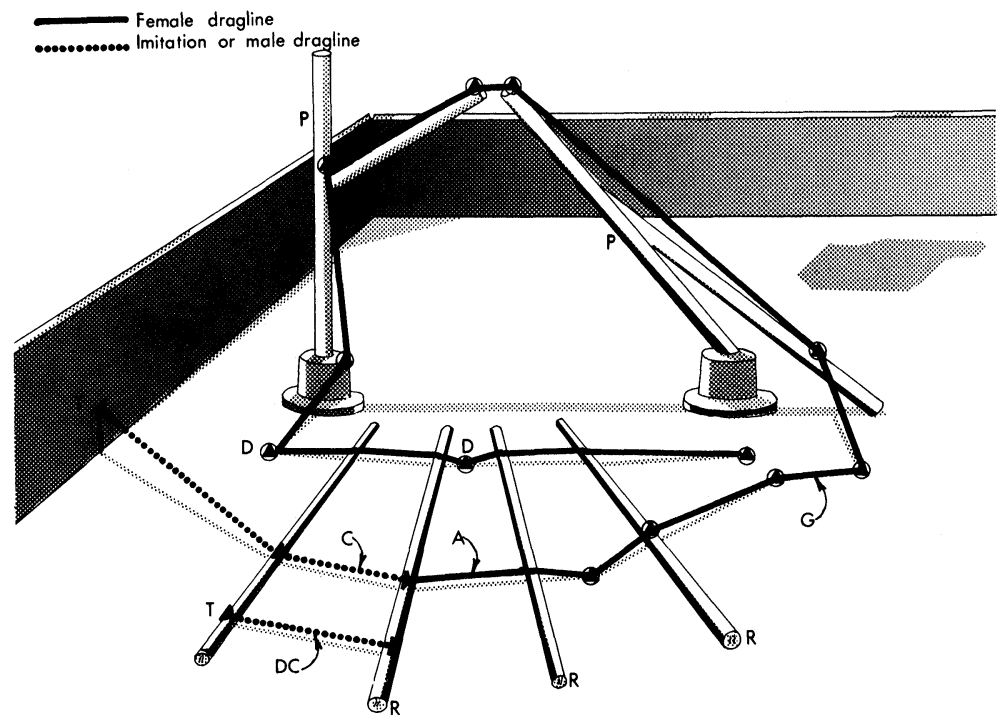

Figure 1. Diagrammatic summary of a typical trail including attachment disks (D) and female aerial lines (A). Female ground lines (G) and imitation draglines are laid contiguously (C) and discontiguously (DC) with the female dragline. Small strips of masking tape $(\mathrm{T})$ attach imitation dragline to the wall of the arena and to 5 - $\mathrm{mm}$ diameter glass rods (R). Glass rods were usually parallel and $9-11 \mathrm{~cm}$ apart. When artificial "plants" $(P)$ were incorporated into the experiment, female trails up to $236 \mathrm{~cm}$ in length were constructed.

dopteran silk or conspecific male or female silk. Male L. punctulata were also exposed to female L. rabida silk. Clean cage cards were used as controls. A positive response by males to the silk consisted of exploring the silk and initiating courtship behavior within $5 \mathrm{~min}$.

Statistical analyses of data were performed according to the methods of Conover (1971) and Sokal and Rohlf (1969). All means are accompanied by their standard errors.

\section{RESULTS}

\section{COMPARISONS OF YEARLY SAMPLES}

No difference was found in trail-following behavior between 1974 and 1976. Unprimed male L. rabida showed no difference in frequency of following-behavior $\left(\chi^{2}=0.0, d f=1, P>.50\right)$ and in 
total distance followed during the 5-min test period (Mann-Whitney test, $T=173, P>.80$ ). Primed male $L$. rabida showed no difference in frequency of following $\left(\chi^{2}=.504, d f=1, P>.70\right)$ or in total distance followed (Mann-Whitney test, $T=229.5, P>.56$ ). Male $L$. punctulata showed no difference in the frequency of following $\left(\chi^{2}=2.5, d f=1, P>.90\right)$ or in total distance followed (MannWhitney test, $T=235.5, P>.84)$. Therefore, data for the two years were pooled for analysis.

\section{DESCRIPTION OF DRAGLINE-FOLLOWING}

Males of both species followed conspecific female lines. Although high speed (36-180 fps) cinematographic analysis indicates that there are slight differences in the use of appendages during dragline-following (Tietjen, unpublished data), the two species exhibit many similarities. Upon contacting the silk line for the first time, males tend to examine it with alternating movements of the palps such that the dorsal surface of the palp contacts the line and moves anteriorly along it. Such behavior is soon terminated if the line is a male's or is an imitation. Dragline-following results if the line is that of a female conspecific. Males usually wander to the edge of the arena and walk around the periphery if chemo- and mechanoexploratory behavior is terminated.

In both species, dragline-following is characterized by the male straddling the silk so that it passes medially beneath him. Although the first pair of legs may occasionally pluck at the line, the palps are the most important appendages used. The palps are alternately moved forward and back, making contact with the silk on their medial surface rather than on the dorsal surface, which is used during the initial contact with the line. Experiments conducted under red light (Kodak safelight Filter No. 1) and with blinded animals indicated that vision is not necessary for dragline-following. Males may accompany their dragline-following behavior with elements of courtship or, more typically, interrupt dragline-following with separate bouts of courtship behavior.

\section{DRAGLINE-FOLLOWING BY LYCOSA RABIDA}

Both primed and unprimed male L. rabida followed female aerial draglines. Unprimed males exhibited a lower incidence of draglinefollowing, with $84.6 \%$ of primed and $65.2 \%$ of unprimed following $\left(\chi^{2}=5.83, d f=1, P<.025\right)$. Comparing only those males that 
Table I: Performance of Male Lycosa rabida and Male L. punctulata During Dragline-Following of Conspecific Male, Female, and Imitation Silk.

\begin{tabular}{|c|c|c|c|}
\hline & \multicolumn{2}{|c|}{ L. rabida } & \multirow{2}{*}{$\frac{\text { L. punctulata }}{\text { Pooled }}$} \\
\hline & Primed & Unprimed & \\
\hline Number of males tested & 52 & 69 & 57 \\
\hline number following & 44 & 45 & 40 \\
\hline number not following & 8 & 24 & 17 \\
\hline \multicolumn{4}{|l|}{ Distance $(\mathrm{cm})$} \\
\hline $\bar{Y}$ total distance & $23.1 \pm 2.3$ & $26.7 \pm .2$ & $56.9 \pm 8.7$ \\
\hline $\bar{Y}$ polarity & $+7.9 \pm 3.3$ & $-6.5 \pm 4.2$ & $+5.3 \pm 2.4$ \\
\hline \multicolumn{4}{|l|}{ Courtship } \\
\hline Frequency & $27.2 \%$ & $26.6 \%$ & $12.5 \%$ \\
\hline $\bar{Y}$ latency (min) & $1.4 \pm .4$ & $1.1 \pm .3$ & $1.4 \pm .8$ \\
\hline \multicolumn{4}{|c|}{ Imitation and male draglines } \\
\hline number followed & 7 & 4 & 0 \\
\hline number not followed & 6 & 12 & 16 \\
\hline \multicolumn{4}{|l|}{ Ground lines } \\
\hline number followed & 0 & 0 & 13 \\
\hline number not followed & 18 & 9 & 4 \\
\hline
\end{tabular}

followed draglines, no significant difference was found in the total distance followed between primed and unprimed animals (MannWhitney test, $T=1069.5, P>.72$ ). No males of either group followed ground lines, although they would usually examine such lines with their palps (Table I).

None of the male $L$. rabida followed isolated imitation draglines; and chemoexploratory behavior to such lines was exhibited only five times. Males in the process of following a female line would occasionally follow imitation and male draglines laid contiguously with the female trail (Table I). Once, a male following a female line continued on and followed the entire length of a human hair that constituted an $8.5 \mathrm{~cm}$ interruption in the female trail, losing no momentum in his following behavior. Male draglines were followed four times, human hairs were followed six times and nylon thread was followed once.

The polarity of each male's trail was calculated as the difference between total distance traveled in the same direction as the female 
trail was laid and total distance traveled in the opposite direction. Primed males exhibited a positive polarity by following the correct direction more often than the incorrect direction $\left(\chi^{2}=7.36, d f=1\right.$, $P<.01)$, and by traveling further in the correct direction along the female trail (Wilcoxon test, $T=252.5, P<.01$ ). Unprimed males did not show a directional preference $\left(\chi^{2}=0.0, d f=1, P>.50\right.$; Wilcoxon test, $T=525, P>.64$; Table I).

Primed and unprimed male $L$. rabida showed no difference in the frequency of courtship during dragline-following $\left(\chi^{2}=.613\right.$, $d f=1, P>.50)$ or in the elapsed time during a test before courtship was observed (= courtship latency) (Mann-Whitney test, $T=$ 70.0, $P>$.54; Table I). Primed males that courted showed no correlation between total distance of dragline followed and courtship latency (Spearman's rho, $\rho=+.026, P>.53$ ). Unprimed males courting early in the test showed decreased total draglinefollowing (Spearman's rho, $\rho=+.692, P<.01$ ). Comparing primed and unprimed males that both courted and followed draglines, no difference was found in the total amount of draglinefollowing (Mann-Whitney test, $T=747.0, P>.65$ ).

\section{DRAGLINE-FOLLOWING IN LYCOSA PUNCTULATA}

L. punctulata was a more difficult species to study experimentally than L. rabida. Females often would not lay the required lines and both sexes tended to break the lines by catching a claw on them, and the males by running through the lines.

In 1974,9 of 10 males in each group exhibited dragline-following. The total distance followed for primed $(\bar{Y}=63.1 \pm 20.7 \mathrm{~cm})$ and unprimed $(\bar{Y}=63.1 \pm 17.5 \mathrm{~cm})$ males did not differ significantly between the two groups (Mann-Whitney test, $T=47.5, P>.57$ ). Incidence of courtship did not differ between the two groups with primed males courting during one and unprimed males courting during three of the trials $\left(\chi^{2}=1.25, d f=1, P>.70\right)$. Data for the two groups were pooled for further analysis.

In 1976 only unprimed males were used. During 34 trials 23 males followed a mean total distance of $52.4 \pm 11.3 \mathrm{~cm}$. No differences were found between pooled 1974 data and the 1976 (all unprimed) data for incidence of following $\left(\chi^{2}=3.41, d f=1, P>\right.$ .05 ), or for distance followed (Mann-Whitney test. $T=235.5, P$ $>$.77). Unprimed males in 1976 exhibited courtship three times during dragline-following; no difference in courtship frequency was 
found between the pooled 1974 data and those for 1976 males $\left(\chi^{2}=0.34, d f=1, P>.70\right)$. In order to have a larger data base the data were pooled for both years.

Unlike male $L$. rabida, male $L$. punctulata initiated draglinefollowing at ground lines and appeared to use their palps in a manner similar to chemoexploratory behavior. Male L. punctulata rarely examined isolated male lines or imitation lines; of 16 that did palpate these lines, none followed them (Table I). Males exhibited a positive polarity $\left(\chi^{2}=4.33, d f=1, P<.05\right)$, and traveled a greater distance in the correct direction along the female trail (Wilcoxon test, $T=255.5, P<.03$ ).

Males that courted during dragline-following showed no correlation between courtship latency and distance followed (Pearson's $r, r=+.700, P>.90)$. No difference in distance followed was found between males that courted during dragline-following and those that did not (Mann-Whitney test, $T=93.0, P>.58$ ). Courtship latency of males placed on a female substratum was affected after dragline-following; those which had recently followed a dragline exhibited a mean courtship latency of $0.66 \pm .29 \mathrm{~min}(N=23)$ compared with $2.30 \pm 0.25 \min (N=20)$ for those which had not (Mann-Whitney test, $T=52.0, P<.0001$ ).

\section{COURTSHIP RESPONSES TO VARIOUS TYPES OF SILK}

Male $L$. rabida courted in response to silk in a female cage in $50 \%$ of the trials. Courtship latency in response to female silk was $2.30 \pm .25 \mathrm{~min}$. The incidence of courtship in response to female silk differed from the courtship frequency in response to a clean cage, lepidopteran silk and male $L$. rabida silk $\left(\chi^{2}=33.99, d f=3\right.$, $P<.001)$. The incidence of courtship did not differ among the latter three conditions $\left(\chi^{2}=2.05, d f=2, P>.70\right)$. (Table II).

Male $L$. punctulata courted in response to female conspecific silk in $61.1 \%$ of the trials and exhibited a mean courtship latency of $2.55 \mathrm{~min} \pm .44 \mathrm{~min}$. The incidence of courtship in response to female conspecific silk, female $L$. rabida silk, lepidopteran silk, a clean cage and male $L$. punctulata silk differed significantly $\left(\chi^{2}=\right.$ 35.93, $d f=4, P<.001)$, while courtship frequency did not differ among the latter four test conditions $\left(\chi^{2}=2.10, d f=3, P>.50\right)$.

To simulate the effects of dew under natural conditions, silk trails of females of both species were sprayed with a fine mist of distilled water and were air dried (= washed lines). Draglines so 
Table II. Courtship Responses to Various Types of Silk by Male Lycosa rabida and Male L. punctulata.

\section{Experimental Silks}

$\begin{array}{ccccc} & \text { Female } & \text { Male } & \text { Female } & \\ \text { Clean } & \text { con- } & \text { con- } & \text { hetero- } & \text { lepidop- } \\ \text { cage } & \text { specific } & \text { specific } & \text { specific } & \text { teran }\end{array}$

L. rabida

number tested

number courting

number not courting

$\bar{Y}$ courtship

latency $(\mathrm{min})$

$20 \quad 40$

40
20

$\begin{array}{lllll}19 & 20 & 20 & - & 20\end{array}$

20

$0 \quad 20$

$\begin{array}{lllll}1 & 20 & 0 & - & 0\end{array}$

L. punctulata

number tested

number courting

number not courting

$1.27 \quad 2.30 \pm .2$

$\bar{Y}$ courtship

latency (min)

$4.06 \pm .7 \quad 2.55 \pm .7 \quad 4.93$

treated lost elasticity and drooped between the supporting glass rods. Both unprimed male L. rabida $(N=10)$ and unprimed male L. punctulata $(N=10)$ exhibited short bouts of chemoexploratory behavior at washed lines, but neither species exhibited courtship or trail-following behavior during the 5-min trials.

\section{DISCUSSION}

Trail-following has been observed in a variety of arthropods. Terrestrial chemical trails are often employed by eusocial insects, but such trails are detected by the receiver as a rapidly decaying vapor cloud above the substratum and provide no directional information (Wilson, 1971). Lepidopteran larvae (Malacosoma, $\mathrm{Hy}$ ponomeuta and Thaumetopoea) have been observed to follow silk trails from their nest to a food source; but tactile information provided by the silk is unimportant, and the pheromone decays within a few minutes (Fitzgerald, 1976; Wigglesworth, 1966). Wolf spider trails differ from the above examples in function (mating vs. food), in the use of a contact rather than an olfactory pheromone, and in the presence of an inherent polarity. Silk lines in the 
laboratory up to 4 days old will elicit following-behavior in male $L$. rabida and male $L$. punctulata; and a cage substratum with female silk elicits courtship behavior for over a month (Tietjen, unpub. data), indicating that the spider pheromone does not decay over a relatively long period of time.

Female lycosid spiders exhibit low motility during the breeding season and adopt a "sit and wait" reproductive strategy; the highly active males seek out the females (Hallander, 1967a, 1967b; Hollander, 1972; Muma, 1973; Richter, et al., 1971). Mathematical modeling of females laying no silk trails and silk trails of various lengths indicates that the presence of silk effectively increases the size of the female target as perceived by the searching male (Tietjen, unpub. data). Thus, the ability of male L. rabida and L. punctulata to follow conspecific female draglines to the source increases the reproductive success of these males over spiders that depend on chance encounters in a heterogeneous environment. Female silk also alerts the male to the presence of a female conspecific and, as shown in L. punctulata, decreases the courtship latency. The latter two functions effectively reduce the likelihood of intraspecific cannibalism (Platnick, 1971).

Contact sex pheromones associated with the female dragline are known to induce courtship in conspecific male spiders (Dijkstra, 1970; Dondale and Hegdekar, 1973; Hegdekar and Dondale, 1969). Results from the present study support the hypothesis that a pheromone associated with the female dragline elicits courtship in receptive males, i.e., these behaviors are not dependent exclusively upon tactile information provided by the silk. Both L. rabida and $L$. punctulata are found with a variety of other spider species. Dependence on a pheromone to elicit sexual behavior in males would reduce the chances of males following draglines of other species and thereby adversely affecting the time budget allocated for reproductive purposes.

The propensity of male $L$. rabida not to follow ground lines which cannot be plucked by the palps (thereby providing little tactile input) and their occasional following of imitation draglines, which provide no chemical cues, indicate that the pheromone is responsible only for initiating the following behavior in males. Once a male is following a dragline, tactile cues appear to be adequate. Males are expected, however, to occasionally sample the trail for female pheromone, as only $38 \%$ of male and imitation 
dragline contacts during female dragline-following resulted in following by males, and most imitation draglines were not followed the entire length.

Male L. punctulata followed ground lines, but did not follow male and imitation draglines. This species appears to depend upon the female pheromone for initiating and for maintaining draglinefollowing. Apparently, male L. punctulata are either more sensitive to tactile input provided by ground lines, or more sensitive to pheromonal cues than male L. rabida, or both.

The differential sensitivity to tactile and chemical cues exhibited by the two species may be related to microhabitat preferences. $L$. punctulata is found in the lower levels of the herbaceous stratum (Eason and Whitcomb, 1965) in which one expects a greater diversity and density of spiders (Whitcomb, Exline and Hite, 1963) and consequently more draglines. Many lycosids of similar or larger size are found within this microhabitat of which male $L$. punctulata could be potential prey, including $L$. helluo and L. carolinensis. Continuous sampling for female pheromone during dragline following reduces the likelihood that males will follow another species' trail in a high silk density microhabitat. In addition, due to the greater foliage density at this level, many draglines could be expected to be laid directly on a substratum. A greater sensitivity to tactile and/or chemical cues could allow male L. punctulata to follow such ground lines.

L. rabida, on the other hand, is found high in the herbaceous stratum (Eason and Whitcomb, 1965; Kuenzler, 1958) and is associated with lower interspecific silk densities derived mainly from smaller species such as salticids and oxyopids. Foliage density is less, and a greater volume of open space is found at this level. Fewer female silk trails would be expected to be found directly on this substratum. Under these conditions the sensitivity to tactile and/or chemical cues exhibited by $L$. punctulata would not be required for efficient dragline-following by male $L$. rabida.

Silk lines are destroyed mechanically in the field by wind and the activities of animals. Moisture resulting from rain and early morning dew inactivates the female pheromone found on unbroken lines (Dondale and Hegdeker, 1973; Hegdeker and Dondale, 1969). All of these effects reduce the likelihood that males will follow draglines laid the previous day. 
Male $L$. punctulata and primed male $L$. rabida may be able to extract directional information from the female dragline, though it is unlikely that a pheromone concentration gradient could provide the directional information since the pheromone remains active over long periods of time. Examination of female L. rabida silk under a light microscope (450 $\times$ ) as well as scanning electron microscope inspection of female $L$. punctulata silk (1000×) indicate no evidence of structural features on the dragline which could provide directional information to males.

Spiders are able to detect slight changes in web tension through vibration receptors during prey capture, web building, and courtship (Robinson, 1969; Walcott, 1969; Witt, 1975). Such variations in tension, related to the direction in which the dragline was laid, could provide directional information to dragline-following males. If present, the tension differential may be related to the structure of the attachment disk by which the silk is fixed to a substratum. As the dragline enters the attachment disk it is tightly wound, whereas the silk leaving the attachment disk is composed of single threads which later join and wind to form the dragline. Single silk threads leaving an attachment disk would be expected to damp transients produced along the line more readily than a complete dragline entering an attachment disk. If this were the case, dragline-following toward the pole with the higher resonant frequency would constitute movement in the direction the silk was laid (Tietjen, unpub. data). Such a system would require that males immobilize a portion of the dragline, perhaps with a palp, while plucking on either side of the fixed portion. Male spiders encountering a female line often wipe the dorsal surface of each palp alternately over the silk and often pluck at the silk with the first legs as they swivel their bodies along a short length of the trail. This behavior may represent both a sampling for female pheromone and a testing for differential mechanical properties of the line related to the direction in which it was laid.

Unprimed male L. rabida did not exhibit a polarity in draglinefollowing, but a positive correlation between courtship latency and total distance followed was observed. The above correlation indicates that unprimed males probably have a lower threshold for chemical cues than do primed males. If unprimed males are attending more to chemical cues, they would be less likely to follow 
a dragline in a preferential direction if directional cues were dependent on the mechanical properties of the line.

\section{SUMMARY}

The dragline-following behavior of male wolf spiders was observed in response to male, female and imitation draglines. Male L. rabida followed female draglines suspended above the substratum but not those laid directly on the substratum. These males followed male silk and imitation lines if laid contiguously with female draglines, suggesting that they depend on tactile cues during dragline-following. On the other hand, male L. punctulata followed both aerial lines and ground lines laid by females but did not follow imitation or male lines. This suggests that male $L$. punctulata are more sensitive to tactile and/or chemical cues than are male $L$. rabida. Microhabitat preferences of the two species may explain the above differences. Data also suggest that males of both species are able to extract directional information from the dragline, perhaps by tensional cues.

\section{ACKNOWLEDGMENTS}

The author wishes to express his gratitude to Dr. J. S. Rovner for his support, valuable discussions and assistance in the preparation of the manuscript. Thanks are also due Dr. W. D. Hummon, Dr. C. P. Spirito and Dr. G. E. Svendsen for their helpful criticism of this work. Anne Tietjen assisted in the preparation of the manuscript.

\section{Literature Cited}

BRistowe, W. S. AND G. H. Locket

1926. The courtship of British lycosid spiders and its probable significance. Proc. Zool. Soc. 22: 317-347.

Conover, W. J.

1971. Practical Nonparametric Statistics. New York: John Wiley and Sons, Inc. $492 \mathrm{pp}$.

Dijkstra, H.

1970. Comparative research of the courtship behaviour on the genus Pardosa (Arach. Araneae) III. Agnostic behaviour in Pardosa amentata. Bull. Mus. Nat. Hist. Natur. 41: 91-97.

Dondale, C. D. and B. M. Hegdekar

1973. The contact sex pheromone of Pardosa lapidicina. Emerton (Araneida; Lycosidae). Canad. J. Zool. 51: 400-401. 
EASON, R. AND W. H. WhITCOMB

1965. Life history of the dotted wolf spider. Lycosa punctulata Hentz (Araneida; Lycosidae). Arkansas Acad. Sci. Proc. 19: 11-20.

ENGELHARDT, W.

1964. Die mitteleuropischen Arten der Gattung Trochosa C. L. Koch, 1848. Z. Morph. Tiere. 54: 219-393.

Fitzgerald, T. D.

1976. Trail marking by larvae of the eastern tent caterpillar. Science 194: 961-963.

HALLANDER, $\mathrm{H}$.

1967a. Courtship display and habitat selection in Pardosa chelata (O. F. Muller). Oikos 18: 145-150.

1967b. Range and movements of the wolf spiders Pardosa chelata (O. F. Muller) and P. pullata (Clerck). Oikos 18: 360-364.

Hegdekar, B. M. and C. D. Dondale

1969. A contact sex pheromone and some response parameters in lycosid spiders. Canad. J. Zool. 47: 1-4.

Hollander, J. Den.

1972. Differential use of the habitat by Pardosa pullata (Clerck) and Pardosa prativaga (L. Koch) in a mixed population (Araneae, Lycosidae). Tijd. Joor. Entomol. 115: 205-215.

KASTON, B. J.

1936. The senses involved in the courtship of some vagabond spiders. Entomol. Amer. 16: 97-169.

KUENZLER, E. J.

1958. Niche relations of three species of lycosid spiders. Ecology 39: 494-500. Muma, M. H.

1973. Comparison of ground surface spiders in four central Florida ecosystems. Florida Entomol. 56: 173-196.

Pi.ATnick, N.

1971. The evolution of courtship behaviour in spiders. Bull. Brit. Arach. Soc. 2: $40-47$.

RiCHTER, C. J. J.

1970a. Morphology and function of the spinning apparatus of the wolf spider Pardosa amentata $(\mathrm{Cl}$.) (Araneae, Lycosidae). Z. Morph. Tiere. 68: $37-68$.

1970b. Aerial dispersal in relation to habitat in eight wolf spider species (Pardosa, Araneae, Lycosidae). Oecologia 5: 200-214.

Richter, C. J. J. AND J. Den Hollander

1971. Differences in breeding and motility between Pardosa pullata (Clerck) and Pardosa prativaga (L. Koch) (Lycosidae, Araneae) in relation to habitat. Oecologia 6: 318-327.

ROBINSON, M. H.

1969. Predatory behaviour of Argiope argentata (Fabricus). Amer. Zool. 9: 161-174.

ROVNER, J. S. AND S. J. KNOST

1974. Post-immobilization wrapping of prey by lycosid spiders of the herbaceous stratum. Psyche 8: 398-415. 
SOKAL, R. R. and F. J. RoHlF

1969. Biometry. San Francisco: W. H. Freeman. 766 pp.

WALCOTT, C.

1969. A spider's vibration receptor: its anatomy and physiology. Amer. Zool. 9: 133-144.

Whitcomb, W. H., H. Exline and M. Hite

1963. Comparison of spider populations of ground stratum in Arkansas pasture and adjacent cultivated field. Arkansas Acad. Sci. Proc. 17: 1-6.

WigGLESWORTH, V. B.

1966. The Life of Insects. London: William Clowes and Sons, Ltd. 360 pp. WILSON, E. O.

1971. The Insect Societies. Cambridge: Belknap. 548 pp.

WITT, P. N.

1975. The web as a means of communication. Biosci. Commun. 1: 7-23. 

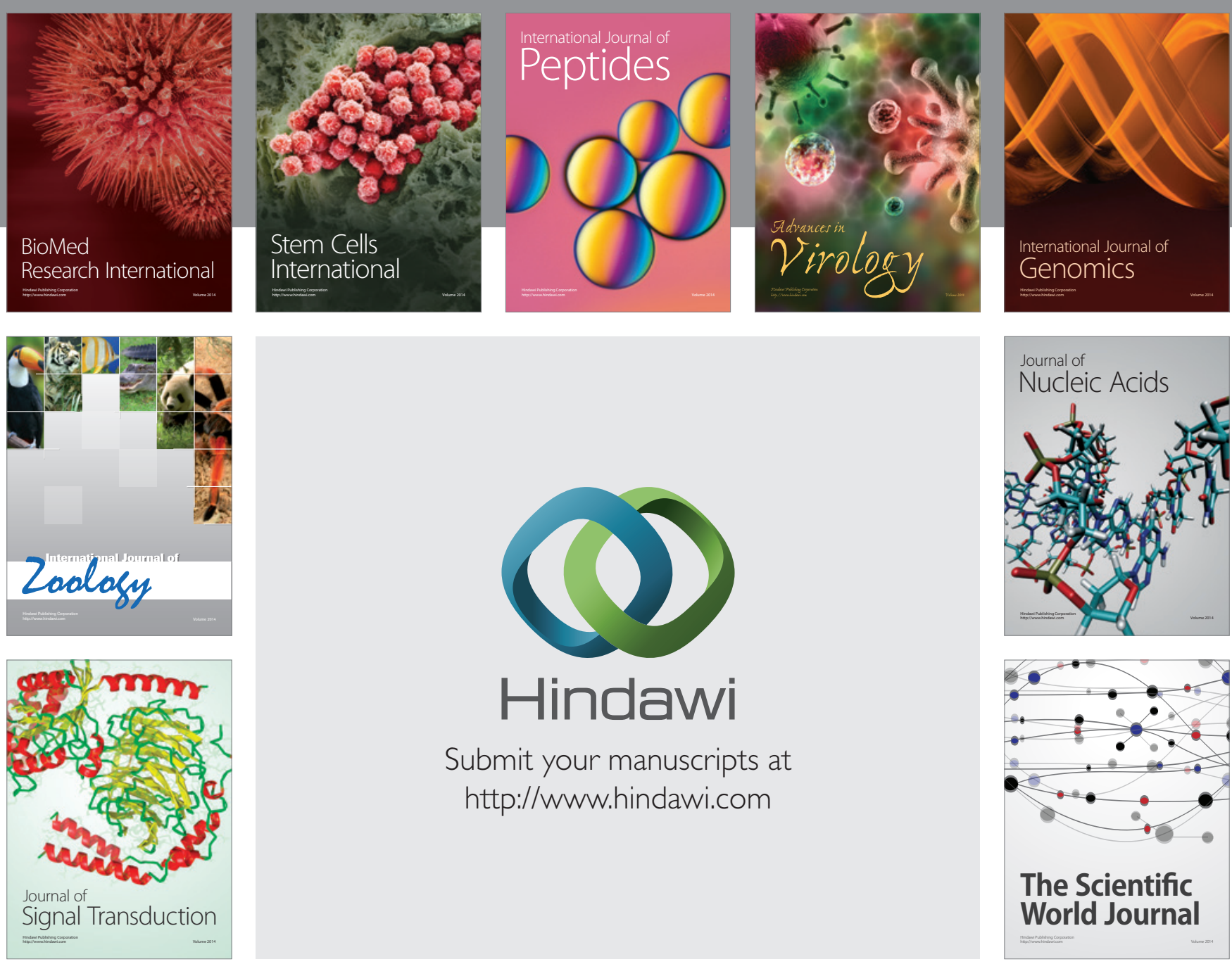

Submit your manuscripts at

http://www.hindawi.com
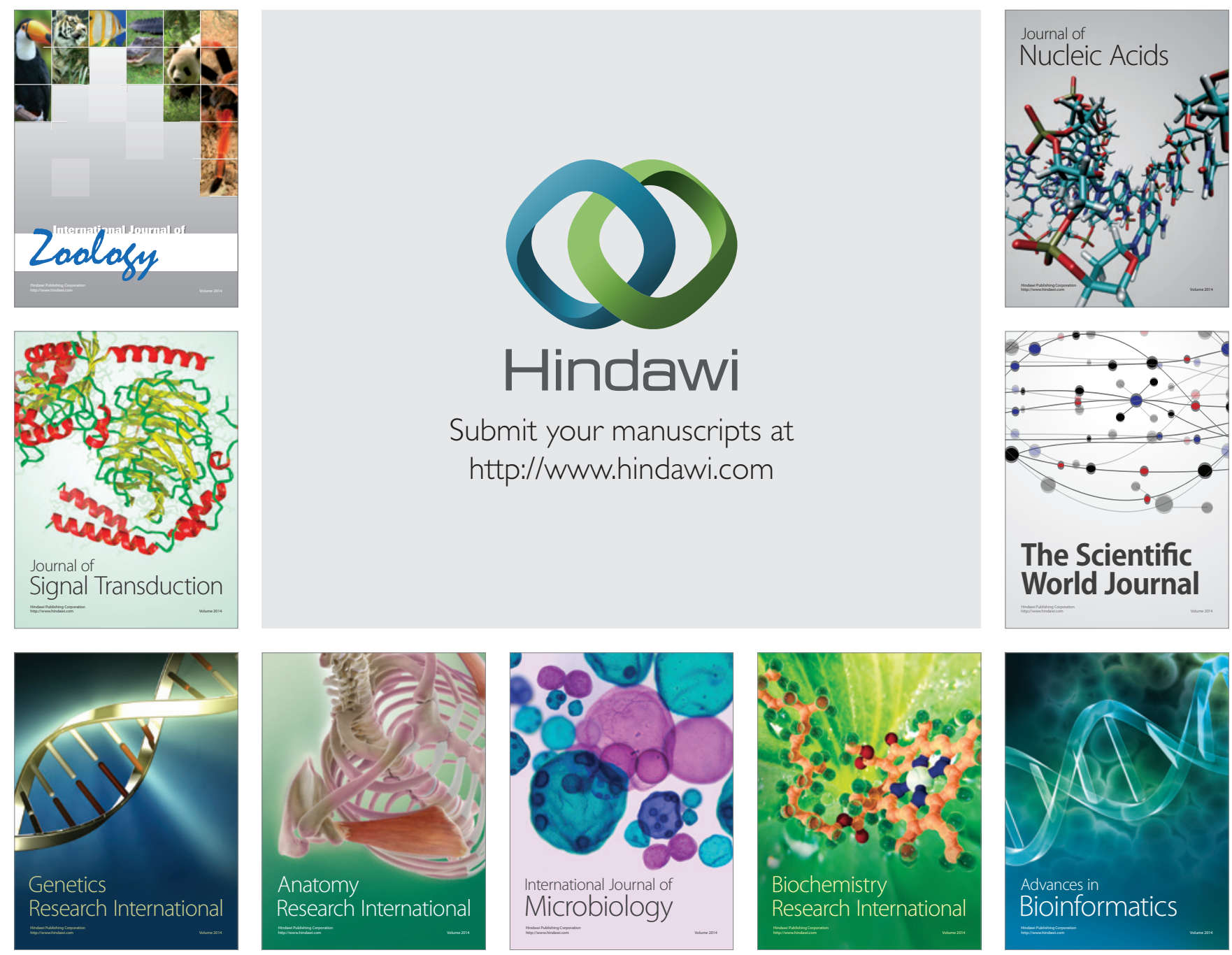

The Scientific World Journal
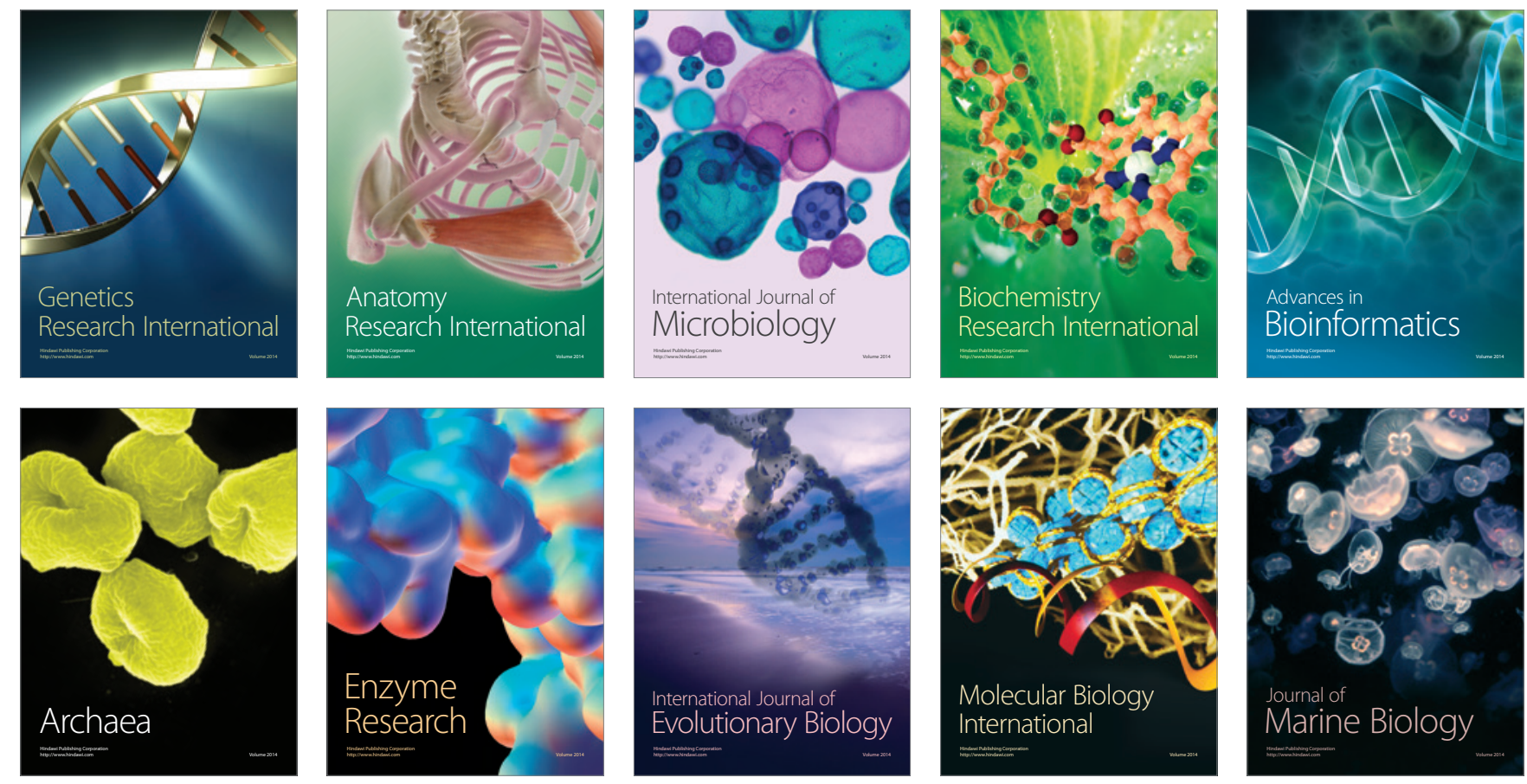